\title{
LOS PÚNICOS EN IBERIA Y LA HISTORIOGRAFÍA GRECOLATINA
}

\author{
THE IBERIAN PUNICS AND GRECO-LATIN HISTORIOGRAPHY
}

\author{
por \\ EDUARDO FERRER ALBELDA
}

\begin{abstract}
RESUMEN Proponemos una ordenación e interpretación de los testimonios grecolatinos relativos a los pobladores de las costas meridionales de Iberia y a su relación con Cartago. Centran nuestra atención los cambios introducidos en la etnonimia a lo largo de este período historiográfico.
\end{abstract}

\begin{abstract}
We propose a disposition and interpretation of the graeco-latins testimonies relating to the Iberian meridional coasts' habitants and their relation with Cartago. The changes introducing into the ethnonimy during this historiographic period centre our attention.
\end{abstract}

\section{INTRODUCCIÓN: LA HISTORIOGRAFÍA PÚNICA}

La literatura grecolatina referente a las comunidades púnicas de Iberia es exigua a pesar de que las costas sudibéricas son las que a menudo aparecen descritas por los geógrafos antiguos y donde normalmente se ubican los episodios míticos e históricos hispanos, con una notable diferencia en relación a otras áreas de la península ibérica (Ferrer 1995: 14-167). A priori sería lógico pensar que una población estable como la fenicio-púnica, que habitó un territorio más o menos extenso de Iberia y que mantuvo una relación continuada con pueblos con tradición literaria como Cartago, el mundo de las colonias griegas o Roma, hubiera dejado un caudal importante de conocimiento directo o indirecto.

Sin embargo, esta restricción documental es un hecho real y se debe a la suma de una serie de factores, entre los que destaca la no por reiterada menos evidente pérdida de todo un conjunto de noticias de origen púnico, sobre todo obras de historiadores griegos al servicio de comunidades o de particulares. De esta pérdida ya se lamentaban los ilustrados españoles (Rodríguez 1766: 265; Lancel 1994: 326) al tener constancia por los mismos autores clásicos de bibliotecas, archivos, crónicas y escritores relacionados con la historia de Cartago. 
Polibio (I, 14), por ejemplo, hace referencia a Filino de Agrigento, narrador de los acontecimientos de la primera Guerra Púnica; y, siguiendo esta tradición, Sileno de Calacte, que según Cicerón (Divinat, Lib. I) redactó una historia de Cartago, y Sosilo de Lacedemonia, profesor de griego de Aníbal, se convirtieron en los historiógrafos de Aníbal.

Asimismo, de la historia escrita de Cartago nos queda constancia por los Libri Punici mencionados por Salustio (Bell. Yug., 17, 7), supervivientes a la destrucción de la ciudad (Krings 1990), y por las citas de Ps. Aristóteles y Servio, que hablan respectivamente de Historia Poenorum y Punica Historia (Moscati 1983: 21). También Avieno (Or. Mar., 414) hace referencia a unos anales púnicos supuestamente conservados hasta el siglo IV, quizás los mismos de los que San Agustín (Ep., 17,2) oyó hablar pero no había consultado (Lancel 1992: 327).

De haberse conservado, hubieran sido también de interés para el conocimiento de las costas de Iberia, de sus ciudades y de sus habitantes, la producción periplográfica y periegética púnica, que debió ser profusa y de la que se conservan algunas referencias como los periplos de Hanón (López Pardo 1990) e Himilcón (Plinio NH II, 169; Avieno Or. Mar., 125).

Por último, otra fuente irrecuperable la debió constituir la documentación escrita custodiada en los templos fenicio-púnicos, como el de Baal Hammon en Cartago o el de Melqart en Gadir, en cuyas columnas estaba inscrita una relación, ilegible para el testigo romano, con un contenido probablemente económico u oracular (García y Bellido 1951: 107).

La realidad de una literatura histórica, geográfica y agronómica púnica parece un hecho incontrovertible, pero de toda esta información, que debió ser vastísima, no queda sino el testimonio de su existencia y la certeza de su irrecuperabilidad.

\section{HISTORIOGRAFÍA GRECOLATINA: CUESTIONES PRELIMINARES}

Otro bloque de documentación literaria, en este caso conservado en una mínima parte, es el que se conoce de manera genérica como "fuentes clásicas" o "grecolatinas", denominaciones que engloban una realidad literaria muy heterogènea, con grandes diferencias cronológicas -cerca de mil años-, de géneros (histórico, geográfico, periegético, periplográfico, poético, cómico), y de autores; pero que, contrariamente a su complejidad, a menudo se considera como un todo homogéneo.

Cierta corriente historiográfica española que perdura hasta la actualidad ha considerado las noticias transmitidas por los autores griegos y latinos como verdades inapelables que deben ser comprobadas arqueológicamente. La sentencia "las fuentes tenían razón" es tan habitual en nuestros escritos que parecen reflejar la dependencia inconsciente del modelo decimonónico de Schliemann de comprobación empírica de una realidad literaria incuestionable. Este "método" tiene especial incidencia en los análisis sobre pueblos protohistóricos de la península ibérica.

En lo que respecta a la problemática de las cofhunidades púnicas, hay factores intrínsecos y extrínsecos a la documentación literaria que dificultan enormemente un acercamiento objetivo. Entre los últimos, el que mayor trascendencia ha tenido a nuestro juicio es el peso de la tradición historiográfica sobre la Hispania antigua, en la que nos hemos formado las últimas generaciones de historiadores y arqueólogos; nos referimos a las Fontes Hispaniae Antiquae (Schulten y Bosch 1922).

La inmensa tarea de reunir todas las referencias a la Península en autores griegos y latinos, ha supuesto en contrapartida cierta esclavitud al modelo schulteniano (García Moreno 1989a: 28), cuyo principal inconveniente -independientemente de las conclusiones históricas a las que llẹgó- es la descontextualización de los textos (Fèrrer 1996: 91 ss.). El éxito de la obra de Schulten, debido en parte a la comodidad que supone un compendio "crítico" de todo lo escrito sobre Hispania en la Antigüedad, y a su adaptación al modelo 
historiográfico nacionalista vigente en España hasta entonces, ha mediatizado los análisis posteriores del fenómeno púnico, singularmente en dos aspectos: selección de la temática y juicio moral. El primero se refiere a la atención centrada casi exclusivamente en el tema político, en los problemas de hegemonía, los bloques antagónicos, el cierre del Estrecho y el imperialismo cartaginés, argumentos tan vigentes hoy como entonces. Y el juicio moral alude a la opinión categórica que merecen los cartagineses y sus actuaciones en Iberia, profundamente negativa para Schulten, a la que se unieron posteriormente los criterios artísticos helenocéntricos que ahondaron aún más en la tipificación de la cultura púnica, artísticamente estéril, como corresponde a una nación o raza de comerciantes (García y Bellido 1954: 463).

Por último, es preciso subrayar, y en esto la obra de Schulten no es enteramente responsable sino que sigue una tradición muy española, la perpetuación del concepto histórico de España como una sucesión ininterrumpida de invasiones y colonizaciones desde su primera población hasta los Reyes Católicos. Los fenicios y cartagineses se suceden en el dominio del sur de Iberia, sin dar a la posibilidad de la formación de una cultura púnica propia, no necesariamente cartaginesa, y sin prestar la debida atención a las formas de contacto entre los semitas y las comunidades autóctonas (Ferrer 1996).

En lo que respecta a los factores intrínsecos a la documentación, son básicamente tres: fragmentación, origen y naturaleza. El primero de ellos condiciona de tal manera las conclusiones históricas, que podemos afirmar que éstas se han elaborado a partir de una colección de fragmentos muchas veces inconexos, de difícil datación y a veces contradictorios. Pero, en todo caso, el estado fragmentario de las noticias se debe a la casualidad y a las circunstancias historiográficas tardoantiguas y medievales. No ha habido una manipulación selectiva.

El segundo factor condicionará en gran medida el significado y el alcance de lo relatado. Al tratarse de autores griegos y latinos, han de ser tenidos en cuenta la concepción y el conocimiento que tenían sobre otros pueblos, según épocas y autores, liberándonos de tópicos como la falta de objetividad de los autores grecolatinos cuando se refieren al mundo púnico (Dubuisson 1983; Càssola 1983). El tercer factor a considerar es la naturaleza misma de los textos, el género literario al que pertenecen, ya que para el lector no debe ser lo mismo enfrentarse a una obra histórica que a una poética, geográfica o cómica, a un original que a un epítome, una paráfrasis o una cita.

\section{EVOLUCIÓN DE LA HISTORIOGRAFÍA GRECOLATINA SOBRE PÚNICOS Y CARTAGINESES Y SU RELACIÓN CON IBERIA}

Antes de realizar el análisis crítico de los testimonios es preciso hacer tres consideraciones:

1. La primera impresión que nos transmite el conjunto de textos conservados es el desequilibrio entre los distintos períodos historiográficos. Esta desproporción no responde por entero a la conservación aleatoria de fragmentos u obras completas, sino que está relacionado también con el mayor o menor interés de autores o de generaciones de escritores por Iberia.

2. Por otro lado, el factor geográfico va a ser un condicionante a la hora de seleccionar temas y ciclos, porque el sur de Iberia coincide a lo largo de la mayor parte de este período con el límite occidental del mundo conocido. Por su lejanía geográfica, el Extremo Occidente cónstituirá un tema susceptible de relatos legendarios y poéticos, pero también será meta o punto de partida de expediciones científicas y periplos. No cabe duda de que los géneros literarios periplográfico y periegético serán los que puedan aportarnos más información.

3. En tercer lugar, hay varios aspectos en la historiografía clásica que debieron influir en las características y en los contenidos de la información emitida: los tipos de conocimiento que los griegos tuvieron de culturas que no eran la suya (Hoz 1989: 26) y sus propios métodos históricos. 
Una última advertencia. No nos hemos servido exclusivamente de una selección de las alusiones a fenicios, púnicos y cartagineses en Iberia, sino que también hemos incluido las descripciones de geógrafos y periégetas aunque en ellas no se haga mención de éstos, para evitar una notable reducción del conjunto de testimonios, y porque partimos de una evidencia arqueológica válida e incuestionable como es el fenómeno de la colonización fenicia en las costas de Iberia.

Con anterioridad al siglo V a.C., la casi totalidad de las noticias sobre el sur de Iberia se refiere a relatos históricos o míticos sobre Tartessos (González Wagner 1986; Hoz 1989), sin que hayan llegado hasta nosotros relatos contemporáneos sobre la colonización fenicia, sin duda existentes porque las fuentes posteriores reflejan de hecho este fenómeno.

Lo cierto es que hasta fines del siglo VI a.C., época en la que Hecateo de Mileto redactó su Periodos $G e ̂ s$, no contamos con los primeros datos de conjunto sobre las costas ibéricas ${ }^{1}$. En cierto modo la obra del milesio representaba la conclusión de la actividad colonizadora griega en el Mediterráneo y el afán de conocimiento por los límites y dimensiones de la tierra, aunque también se ocupó de las etnias, de las ciudades y sus habitantes (Mazzarino 1966: 70-73), con el objetivo de reflejar por escrito la verdad en contraste con las fábulas que proliferaban en su época (Alemany 1909: 467).

Desconocemos las fuentes en las que se basó para redactar su obra, probablemente un conjunto de informaciones en las que se incluían roteros y referencias orales, pero se tiene la certeza de que es el primer relato que trató sistemáticamente las tierras occidentales (Hoz 1989: 30). La dificultad mayor de la obra de Hecateo reside en que sólo se conservan fragmentos aislados en la Etniká de Esteban de Bizancio, un lexicógrafo del siglo VI. No obstante su información se puede dar como válida de manera general porque su atención no se centra en la discusión de problemas étnicos o geográficos sino en controversias terminológicas.

Los fragmentos conservados nos dan una imagen incompleta de los principales pueblos que habitan la costa sur y este de Iberia: los tartesios (Jacoby 1968: 16), los elbestios (FGrHist 40), los mastienos (FGrHist 41) y los iberos, en sentido oeste-este. Los mastienos, según la cita, ocuparían un área cercana a las Columnas de Heracles y a la costa mediterránea meridional, pues son citadas como mastienas las poleis Suel, Menobara, Sixo y Molibdano, además de la misma Mastia, casi todas identificadas con fundaciones fenicias (García Moreno 1993; Iniesta 1989). También son citadas las poleis tartesias Elyburge, Ibylla y Calathe (FGrHist 39), ésta última próxima al estrecho de Gibraltar.

La historiografía griega posterior, la que abarca prácticamente los siglos V, IV y III a.C., ofrece pocas oportunidades para profundizar en el conocimiento sobre el Extremo Occidente. Tradicionalmente, sobre todo a partir de las tesis de Schulten, este fenómeno se ha explicado por el bloqueo cartaginés del Estrecho y la política de monopolio comercial, opinión que se fundamentaba en las numerosas referencias a la impenetrabilidad de la región allende las Columnas de Heracles contenidas fundamentalmente en la obra de Píndaro (Domínguez Monedero 1988).

1. La Carta de la Tierra de Hecateo finalizaba con la descripción en dos libros de las costas del Mediterráneo desde el mar Negro hasta las Columnas de Heracles, que posteriormente tomarían el nombre de Periégesis (Villalba 1985: 45). 
También se ha insistido recientemente en la pérdida de muchas obras y en la aleatoriedad de esta pérdida (Hoz 1988: 30); no obstante, creemos que también es preciso valorar la mentalidad y la metodología literaria griegas. El interés de los helenos por otros pueblos se plasmó en una ciencia, la Etnografía, saber que, generalizando, se "limitaba a constatar una sentida convicción griega: la diferencia sustancial e insuperable entre los helenos y los bárbaros" (Fernández Ubiña 1986: 139). Si además valoramos que el método histórico que impone Tucídides en el siglo $\mathrm{V}$ a.C., y que perdura hasta la época helenística, prescinde de la etnografía (Momigliano 1984: 13; Plácido 1986) en favor de la observación directa de los hechos contemporáneos, comprenderemos porqué los datos escasean y porqué se incluyen en periplos o en reelaboraciones de obras anteriores.

A este fenómeno añadiríamos la lejanía de estas tierras, fuera del circuito comercial griego. Sin cuestionar contactos intensos, viajes griegos a Occidente (Pitias y Eutimenes) o actividades comerciales greco-púnicas conjuntas (Fernández Nieto 1992: 129 ss.), lo cierto es que las costas atlánticas y mediterráneas meridionales de Iberia estuvieron incluidas dentro del universo púnico hasta el ocaso de Cartago, hecho que sin duda repercutió en el desconocimiento o en el desinterés general por estos territorios.

Heródoto (III, 15), que es anterior a Tucídides y que por lo tanto utilizó la etnografía como fuente de sus Historiai, reconoce su ignorancia sobre el Extremo Occidente, a pesar de residir en la Magna Grecia, donde posiblemente redactó su obra (Rodríguez Adrados 1986: 15); y expresa su desconfianza en obras anteriores (IV, 36), de ahí que los pocos relatos que comenta se dediquen a la cuestión tartésica, un tema con cierta tradición en la historiografía anterior pero tratado de manera anecdótica y supeditado al argumento de la colonización focense (Hoz 1988: 31; Plácido 1993).

Del resto de las noticias datables en el siglo $\mathrm{V}$ a.C., destacan las proporcionadas por Herodoro de Heraclea, a través del bizantino Constantino Porphirogeneta (De administrando imperio 23; FGrHist 2a). Los pueblos que habitarían las costas próximas a las Columnas de Heracles serían los tartesios, los elbisinios y los mastienos, relación que recuerda la descrita medio siglo antes por Hecateo ${ }^{2}$.

Otros testimonios que tienen un origen bien distinto pero igual importancia son las referencias a las salsas de pescado de Gadir proporcionadas por Eupolis (en Esteban de Bizancio), comediógrafo ático de la segunda mitad del siglo V a.C., y por su contemporáneo Aristófanes (Ranas 473). Ambos textos son particularmente interesantes porque se refieren a la fama de las salazones gadiritas en el Atica -extremo que ha podido ser confirmado arqueológicamente-, pero sobre todo porque están insertos en pasajes cómicos que expresan su popularidad en aspectos de la vida cotidiana como el gastronómico, y están libre de cualquier carga ideológica que pudiera poner en duda su historicidad.

\section{III}

"En general, las fuentes posteriores, hasta la segunda guerra púnica, sólo aportan ecos de los conocimientos adquiridos por los griegos en el siglo $\mathrm{V}$, cuya sistematización seguía dependiendo de la realizada por Hecateo, y por lo tanto estaba marcada por lo que pudiéramos llamar "visión de periplo" (Hoz 1988: 34). Ciertamente los testimonios del siglo IV a.C. redundan en las cuestiones que ya hemos planteado. La fama de la salazón de Gadir no decreció a juzgar por su reaparición en comedias de autores áticos como Antífanes o Nicóstratos (Edmonds 1957); este último autor introduce como dato de interés el posible contrabando de este producto en Grecia.

2. Heródoro es un mitógrafo de la segunda mitad del siglo $\mathrm{V}$ a.C. que redacta una extensa historia de los viajes de Heracles, argumento que utiliza como pretexto para dar su visión geoetnográfica del mundo conocido (FHA II, 37-38; Hoz 1988: 33-34). 
La descripción de las costas de Iberia ocuparán a tres autores contemporáneos: Teopompo, Ps. Escilax y Eforo. El testimonio de Teopompo (FHA II, 52-53), transmitido nuevamente por autores tardíos como Esteban de Bizancio o Ateneo, hace referencia a una ciudad, Massía, y a su situación geográfica, distinta del solar ocupado por los tartesios ${ }^{3}$.

En cuanto el periplo de Pseudo Escilax, los autores que han estudiado la obra no han llegado a un acuerdo sobre la autoría y la fecha de la redacción ${ }^{4}$, pero lo cierto es que parece reflejar un contexto de mediados del siglo IV a.C. en muchos pasajes. En la descripción de las costas del sur de Iberia sólo se hace referencia a las islas de Gades, a las Columnas de Heracles, a la existencia de mercados cartagineses más allá del Estrecho y a los terrores del Océano para el navegante. Parece que se trata de un claro ejemplo de tipificación del Extremo Occidente, en el que se utilizan fórmulas y lugares comunes.

El tercer autor aludido es Eforo, historiador que ofreció una visión de conjunto de la tierra conocida en un compendio de treinta libros, hoy perdido, denominado Historiai. Los libros IV y V los dedicó a la descripción de lugares y pueblos, adoptando la forma de un periplo de todo el Mediterráneo, desde Gibraltar hasta el mar Negro. Probablemente los asentamientos fenicios de Iberia y de Libia fueron tratados en el contexto de la discusión general sobre los continentes y sus habitantes (Schepens 1985), pero sólo se ha conservado-en Esteban de Bizancio-la mención a una ciudad cercana al Estrecho, Calatus(s)a (la Calathe de Hecateo), y la idea de una población de etíopes en las costas de Iberia (Estrabón I, 2, 26).

La versión de Eforo sobre la historia universal ejerció una notable influencia en los autores posteriores, pero no hay que perder de vista que Eforo fue un "armchair historian", que no conocía aquello que describía, por lo que tuvo que valerse de fuentes previas, sobre todo griegas, aunque no se descarta que utilizara obras púnicas (Schepens 1985: 329). Por lo demás, según denunciaron algunos autores posteriores, en la obra de Eforo fueron incluidos numerosos errores conceptuales, como la consideración de que los celtas habitaban toda Iberia, reduciendo a los íberos al perímetro de una ciudad (Alemany 19.09: 472).

La información que resta del período anterior a la segunda Guerra Púnica y a la ocupación romana es prácticamente inexistente. Generalmente se incluye en este período el tratado pseudo-aristotélico De mirabiles auscultationes, como atribuido a Timeo (Frutos 1991: 94), cuya obra perdida, en la que se incluía una descripción de Occidente, se data a comienzos del siglo III a.C. No hay unanimidad sobre la fuente que pudo inspirar este tratado (Hoz 1971), pero la identidad de algunos pasajes con otros de Diodoro Sículo, y la atribución de éstos a Posidonio y, a través de él, a Timeo, hacen verosímil esta opinión.

Los datos que nos interesan están contenidos en los fragmentos 136 y 84 del tratado, referentes, respectivamente, a la pesca, trasformación y transporte de productos marinos en Gadir con destino a Cartago, ciudad exportadora y, a la vez, consumidora de tales productos ${ }^{5}$, y a las navegaciones de los cartagineses más allá del Estrecho y su interés por mantener en secreto algunos descubrimientos realizados en el Océano. Este testimonio parece reflejar la actividad cartaginesa y sus intereses en el área del Estrecho a mediados del siglo IV a.C.

3. Esta apreciación se extrae de la lectura de los códices griegos conservados, en los que se especifica que Massía khorá apokeiméne tois Tartesiois, frente a la versión corregida de Schulten (Massía khorá hypokeiméne tois Tartesíois), donde la palabra apokeiméne es sustituida por hypokeiméne, cambio que supone una transformación radical del sentido del texto, que pasaría evidenciar el sometimiento de la ciudad a los tartesios (Alemany 1909: 476; Gil 1986: 378-380; Ferrer y Bandera 1997).

4. El autor del periplo se denominó a sí mismo Escilax, lo que ha hecho pensar a algunos en el periégeta contemporáneo de Heródoto Escilax de Carianda, almirante de Darío I y autor de varios periplos. Sin embargo, la mención de ciudades cuya fecha de fundación es conocida y la omisión de otras que habían sido destruidas, así como el contexto general del periplo, han posibilitado la datación de la redacción entre 361 y 357 a.C. (Fabre 1965: 353-366). No obstante, otros autores estiman que la obra original de Escilax de Carianda sirvió de base para una puesta al día del periplo a mediados del siglo IV a.C. (Casariego 1949: 133; Paretti 1983).

5. Hemos utilizado la traducción corregida por G. Chic que aparece en Frutos y Muñoz 1994: 406 
El conjunto de testimonios posteriores a la segunda Guerra Púnica es cuantitativamente más importante. Se trata en muchos casos de noticias de autores griegos y latinos que han visitado Iberia y que dispusieron de un caudal importante de conocimiento directo. En otros casos se continúa la tradición periegética precedente, ajena a la realidad geoetnográfica de ese momento e inserta en unos géneros literarios visiblemente esclerotizados. En esta tendencia puede incluirse la obra de Escimno de Quíos, geógrafo del siglo II a.C. admirador e imitador de Apolodoro, al cual se le atribuye la redacción de un manual de geografía en verso destinado a las escuelas. En ningún caso el autor del poema describe el estado de Iberia en el momento de la redacción, sino que se retrotrae a tiempos anteriores, adornando el recorrido con pasajes míticos y algunas novedades (Alemany 1910: 20). Sitúa en las costas andaluzas: 1) la isla de Eritia, donde hay una colonia de etíopes y rebaños de bueyes; 2) la ciudad tiria de Gadira, con monstruos marinos, y 3) la ilustre ciudad de Tartessos, localizada a dos días de navegación de Gadira (Scymn. 150-164).

En otros versos (Scymn. 196), ubica a orillas del mar Sardo a los libiofénices, colonos cartagineses, a los tartesios y a los iberos ${ }^{6}$. Con la introducción de los libiofénices, un grupo étnico desconocido hasta ahora en Iberia, trastoca el orden "tradicional" establecido por Hecateo: tartesios, elbestios, mastienos e iberos. La impresión que transmite la obra es la de una falta de coherencia en la redacción, en la que no se ha seguido una fuente única ni una norma geográfica sino mezclado varias tradiciones inconexas.

En el extremo opuesto está la figura de Polibio, el historiador megalopolitano cronista de las conquistas romanas del siglo II a.C. La concepción historiográfica de Polibio está muy relacionada con la creciente hegemonía romana en el Mediterráneo, cuyas causas intenta desentrañar mediante el recurso a un modelo interpretativo cercano a la filosofía peripatética (Díez Tejera 1981: 24). El eje argumental de sus cuarenta libros, titulados Historiai, es la expansión romana, y sus objetivos establecer el cómo, el cuándo y el porqué de los acontecimientos bélicos y políticos, aunque también tuvo inquietudes geográficas y literarias, no siempre acompañadas de una sólida formación (Vallejo 1954: 281).

La realidad histórica abarcada en su obra coincide con el desequilibrio de fuerzas en el Mediterráneo en favor de Roma, apareciendo el mundo púnico como complemento argumental, en el momento en que la presencia cartaginesa en Iberia toca a su fin. No obstante, Polibio proporciona algunos datos de interés sobre la situación previa a la segunda Guerra Púnica. En el primer libro, capítulo introductorio del verdadero argumento y antecedente explicativo de los acontecimientos posteriores, y en el contexto previo a la primera Guerra Púnica, Polibio (I, 10, 5-6) enumera las posesiones de Cartago en el Mediterráneo, entre las que incluye muchos territorios de Iberia. La cuestión que centra la atención de Polibio es en realidad la inseguridad de Roma ante el poderío cartaginés, el "pretexto" de su ulterior actuación, y no una enumeración de los dominios cartagineses. Podríamos pensar incluso en una dramatización de la situación para justificar la guerra. No obstante, el texto es muy explícito y los dominios cartagineses coinciden con la extensión de la cultura púnica, y no hay porqué dudar del dato ${ }^{7}$.

6. Esta descripción de la costa es contraria a las reglas del género periplográfico por el incumplimiento del orden geográfico, y en ella parecen confluir varias tradiciones literarias, una mítica -como la mención a los rebaños de bueyes de Eritia, que parece remontar a Hesíodo y a Estesícoro de Himera (González Wagner 1986: 209-210) o los terrores del Océano-, y otra "histórica", procedente de autores anteriores como Eforo.

7. La historiografía española ha interpretado este pasaje de manera desigual. Schulten opinaba que después del 340 a.C. el poderío cartaginés sobre España decayó hasta perder el control total hacia el 300 a.C. (FHA II, 71 y 125); Gzlez. Wagner (1983: 230 y 340) apuesta por la aplicación de los modelos de "imperialismo indirecto" de Whitakker y de "port of trade" de Polanyi, que llevan a considerar al sur de Iberia como un campo de operaciones del comercio cartaginés, donde no tiene cabida la conquista. Recientemente G. de Frutos (1991: 115 ss.) retoma el papel activo de Cartago en los asuntos hispanos, enlazando el texto de Polibio con datos como las destrucciones de los poblados ibéricos de Andalucía y Levante en un intento de orientar la política interna de los centros indígenas. 
El problema interpretativo se centraría en el significado de los conceptos "someter" y "muchos territorios de Iberia", y en las fuentes en las que se pudo inspirar Polibio. En este sentido, es probable que el historiador conociese las obras de autores que habían tratado de Iberia, como Eforo o Timeo, aunque éste último es criticado con frecuencia por él (Díez Tejera 1981: 40). También debió manejar, porque él mismo las cita y las critica (I, 14), las obras de los historiadores de la primera Guerra Púnica, Fabio Píctor y Filino de Agrigento, representantes de la tradiciones romana y filopúnica respectivamente ${ }^{8}$.

La conclusión a la que llegamos después de la lectura de este pasaje no va más allá del convencimiento de que Polibio y los autores que le sirvieron de fuente para los asuntos de Iberia, sobre todo Eforo y Timeo, consideraban que parte de Iberia estaba sometida a Cartago de la misma forma que el resto de las regiones mencionadas.

Por contra, si puede sernos útil para analizar el tipo de sometimiento el conocido pasaje del libro III que refiere el segundo pacto entre Roma y Cartago (III, 24). Este tratado, junto con el que le precede y los que le suceden, es sacado a colación para referir las responsabilidades y compromisos de ambos estados desde el principio. Es opinión unánime que el autor, durante su estancia en Roma, consultó directamente estos textos grabados en placas de bronce custodiados en el tabularium de los ediles curules sito en el templo de Júpiter Capitolino (III, 26), y que la cita es una transcripción literal del original latino, con lo que en realidad manejamos un documento legítimo de mediados del siglo IV a.C., con datos extraídos posiblemente de una fuente púnica (Hoz 1988: 35; García Moreno 1989: 292).

No obstante, las dificultades que presenta el texto no son pocas, partiendo de la misma transcripción de Polibio del bronce original (Walbank 1957). De estas cuestiones, sólo comentaremos aquellas relacionadas con Iberia:

1. El segundo tratado tendría como novedad respecto del de 509 a.C. la ampliación de la prohibición de practicar la piratería, el comercio y fundar ciudades a los romanos y sus aliados más allá de Mastia Tarseion (en el comentario inicial del autor) o de mastias tarseiou (en la transcripción del texto original latino) ${ }^{9}$. La traducción del fragmento admite varias posibilidades: "más allá del cabo Bello, de Mastia y de Tarseyo", "más allá del Cabo Bello, de Mastia de los tartesios" o bien "más allá del cabo Bello, de Mastia, de los tartesios". De éstas, las que nos parecen más pausibles son la primera o la última, porque en todas las fuentes griegas del siglo V y IV a.C. ya comentadas se menciona la ciudad de Mastia o el pueblo homónimo, los mastienos, como diferentes de los tartesios (Ferrer y Bandera 1997). Las restricciones geográficas del tratado estarían enumeradas, pues, de este a oeste, y quedarían cerrados al comercio romano Cerdeña, el norte de África excluida la metrópoli, y la región situada más allá de Mastia y del pueblo de los tartesios.

2. El segundo problema es la ubicación de Mastia. La ecuación Mastia=Cartago Nova, casi unánimemente admitida por la investigación contemporánea, no tiene en nuestra opinión ninguna base (Ferrer y Bandera 1997). En la historiografía clásica jamás se da esta equiparación, ni siquiera se insinúa cuando es relatada la nueva fundación, y tampoco se admite en la historiografía española anterior al siglo XX. La hipótesis parece que tiene su origen en la literatura germánica decimonónica, estando ya admitida en Schulten (1945: 54) y por la investigación posterior sin mayor discusión.

8. Sobre la cuestión de cuál de las dos fuentes prevaleció sobre la otra en la redacción polibiana, el estudio ya clásico de $\mathrm{P}$. Pedech (1952: 246-266) concluye que, aunque conoce ambas versiones, no se fundamenta en ninguna de ellas, sino que probablemente se valió de múltiples fuentes, entre ellas la de un "écrivain spécialiste des questions navales, du genere de ce Zénon de Rhodes". Llega a esta conclusión después de analizar exhaustivamente los pasajes de Polibio y los correspondientes a los mismos sucesos en Diodoro quien presumiblemente utiliza a Filino.

9. El mayor problema reside en que la transcripción no tiene puntuaciones ni mayúsculas, por lo que su correcta lectura y entendimiento es complicada (Hoz 1988: 35), a lo que se puede añadir que es posible que Polibio no comprendiera bien el latín arcaico del texto ni la geografía que describía (García Moreno 1989: 292). 
Recientemente, García Moreno (1993: 211) ha cuestionado con argumentos razonables esta hipótesis, llegando a la conclusión de que Mastia debió situarse en las inmediaciones de Gibraltar (también Silgo 1992: 371). Admitir esto no conlleva más problemas que trasladar el límite de la prohibición hasta el Estrecho, y admitir el interés de los cartagineses en la salvaguarda de sus intereses económicos y comerciales en esta área.

3. La tercera cuestión es el tipo de relación entre Cartago y los territorios mencionados. ¿Quiénes eran esos aliados además de los tirios y los uticenses? ¿Podemos considerar a mastienos y tartesios entre ellos? En todo caso es incontrovertible el papel de Cartago como tutor de estos territorios al atribuirse la potestad de pactar con otros estados y poner límites geográficos al comercio. No obstante, no podemos precisar si esta autoridad traía consigo un dominio efectivo, con guarniciones y aparato administrativo cartaginés, o contrariamente los púnicos de Iberia gozaban de una amplia autonomía en calidad de aliados.

Otro pasaje de las Historiai (II, 1, 5-9) se presta a analizar la relación de Cartago con los púnicos de Iberia, ya que especifica que Amilcar Barca "atravesó las Columnas de Hércules y recobró para los cartagineses el dominio de España" (Balasch 1981). Si Polibio habla de recuperación del dominio es porque lógicamente en el momento inmediato al desembarco cartaginés tal dominación no existía, pero había existido con anterioridad, deducción que ha originado toda una corriente de especulación sobre cómo y cuando perdió Cartago el control del territorio.

En nuestra opinión, para conocer el contexto previo a la conquista bárquida es imprescindible revisar los últimos tratados firmados entre Roma y Cartago ${ }^{10}$, en los que no se introducen cambios que afecten a Iberia. ¿Cómo conciliar, pues, los conceptos coetáneos de "dominio" y "restablecimiento" en Polibio?.

La aparente contradicción se podría solucionar si analizamos las campañas de Amílcar en Iberia: el general desembarca pacíficamente en Gadir según Diodoro (XXV, 10) y Apiano (Iber. 5) y lucha contra tartesios, iberos y celtas, a los que sometió a la fuerza o mediante pactos (Polibio II, 1, 5-7; Diodoro XXV, 10). Las fuentes no hacen alusión alguna al sometimiento de mastienos, de Gadir o de otros pueblos y ciudades de la costa, porque con seguridad esta región seguía fiel a la órbita cartaginesa. El "restablecimiento del dominio" de Polibio no afectaría a los territorios costeros de honda raigambre semita, sino a las regiones y vías de comunicación de las que dependía especialmente el suministro de metales. La situación internacional había cambiado de tal forma que se hacía necesario un férreo control del territorio, para lo que hubo que recurrir a la conquista, a la fundación de ciudades y a la agilización de la diplomacia, en especial a la política matrimonial.

\section{$\mathrm{V}$}

La historiografía grecolatina del siglo I a.C. ha proporcionado algunos datos de interés sobre los pobladores de Hispania, casi todos recogidos en la obra de Estrabón. El autor, que no visitó la Península, hizo acopio sin embargo de toda la documentación disponible en su época sobre Iberia. El Libro III de la Geographiká está dedicado a Iberia, a la que describe a través de un recorrido que comienza por las costas suratlánticas portuguesas y andaluzas. Aporta, entre otros, los siguientes datos:

1. Los habitantes del área del Estrecho se denominan bastetanos o bástulos. Carteia es un importante puerto bastetano (III, 1, 7).

10. III, 25, 1-4 y III, 27, 1-9. El tratado del 279 a.C. respeta el statu quo anterior y añade una cláusula coyuntural ante el peligro inminente de una guerra con Pirro de Epiro. Tampoco hay un cambio de la situación en el Extremo Occidente textualmente documentado tras las sucesivas pérdidas de Sicilia y Cerdeña. 
2. Los bastetanos pueblan además la franja costera que se extiende desde Gibraltar hasta el río Guadiana. También habitan en la Turdetania (III, 2, 1).

3. “... su sujeción a los phoinikes fue tan completa, que hoy día la mayoría de las ciudades de Tourdetania y de las regiones vecinas están habitadas por aquellos" (García y Bellido 1945: 100). Los fenicios dominaron la mayor parte de Iberia y de Libia desde los tiempos de Homero hasta la destrucción de su hegemonía por los romanos (III, 2, 14). Se identifican, pues, fenicios y cartagineses.

4. Volvemos a encontrar a los bastetanos o bástulos habitando la costa mediterránea desde Gibraltar hasta Cartago Nova (III, 4, 1).

A partir de los testimonios de Estrabón, no queda más opción que identificar a los bastetanos ${ }^{11}$ con los púnicos de Iberia.

Geógrafos posteriores a Estrabón, como Mela o Plinio, inciden en algunos aspectos ya señalados. En Mela (II, 96) aparecen los mismos hitos que en Estrabón: Carteia es una ciudad habitada por fenicios trasladados de África, y la costa atlántica andaluza está habitada por bástulos y túrdulos. Por su parte, Plinio precisó de mucha información para cumplir su ambicioso proyecto, dejando poco lugar a la investigación personal, y comportándose a veces como un mero compilador (García y Bellido 1947: 85). Por ello recoge sin espíritu crítico la noticia de Agripa sobre la pertenencia de las costas de Iberia a los púnicos, o la referencia de Varrón a la ocupación de la Península por iberos, persas, fenicios, celtas y púnicos ( $N H$ III, 8). Asimismo considera que los bástulos habitan la costa sur de Iberia (NH III, 19).

La tradición geográfica posterior redundará en estas impresiones. Ptolomeo, autor del siglo II, habla de los "bástulos llamados púnicos" (II, 4, 6), como si fueran dos denominaciones distintas de un mismo grupo étnico; Apiano (Iber. 56) menciona a los blastofenicios, y Marciano de Heraclea, ya en el siglo IV, se refiere a los bástulo-poenos. Estas dos formas mixtas se deben a nuestro entender a la unión sintáctica entre dos términos que significan lo mismo, más que a un fenómeno de mestizaje entre dos pueblos diferentes.

Volviendo al tema de las relaciones entre Cartago y la Iberia púnica, la obra de Diodoro de Sicilia, titulada Bibliotheke, es la última que ofrece algunos datos de conjunto. Aunque para nuestros fines la información que proporciona es sólo tangencial, ya que los objetivos de su obra no fueron la descripción de las partes del mundo ni la historia de los confines de la tierra, sino la realización de una historia universal vista a través del prisma de un griego que ha conocido la consolidación paulatina de la hegemonía romana (Sacks 1990), es lógico que Cartago ocupe un papel protagonista, como potencia mediterránea que fue, enfrentada en tres grandes ocasiones a Roma.

Los hechos narrados en la Bibliotheke se localizan habitualmente en Sicilia, escenario de la larga lucha entre griegos y púnicos. Este, junto con las acciones de los Barca y los acontecimientos de la segunda guerra púnica, será temas muy recurridos por la historiografía española ya que aparecen mencionados en ocasiones mercenarios "españoles" (iberos, baleares, etc.) al servicio de los ejércitos púnicos, muy alabados por su valentía y bravura.

No obstante, y a pesar de la imprecisión cronológica en la que muchas veces el autor enmarca sus relatos, hay datos que pueden atribuirse al período prebárquida, como los contenidos en el pasaje que se refiere a la explotación "muy antigua" de las minas hispanas, que sirvió para financiar las guerras contra

11. La existencia de dos áreas habitadas por bastetanos es un hecho fuera de toda duda. Unos pueblan la franja costera andaluza y otros las sierras penibéticas (III, 4, 12 y III, 4, 14). 
los romanos, sículos y los pobladores de Libia $(\mathrm{V}, 38,2)$. Los hechos narrados se remontan a los siglos $\mathrm{V}$ y, sobre todo, IV y III a.C., fechas estas últimas que coinciden con la cronología de las principales fuentes de Diodoro, Eforo y Timeo (Drews 1969).

Este pasaje, junto con el que narra la falta de credibilidad de las noticias del Extremo Occidente por la actitud agresiva de los cartagineses hacia los navíos extranjeros que viajan hacia Cerdeña y las Columnas de Hércules $(\mathrm{V}, 20)^{12}$, expresan el interés de los cartagineses por mantener dos zonas bajo su estricto control: Cerdeña y Gibraltar, aspecto vuelto a confirmar por la versión polibiana del segundo tratado entre Roma y Cartago, que como dijimos es un documento del siglo IV a.C.

Redunda en la idea de la intromisión de Cartago en los asuntos de la Iberia púnica la narración de Vitruvio sobre la invención del ariete en el asalto cartaginés a Cádiz (De architectura X, 19) ${ }^{13}$, un pasaje problemático ya que para el autor este relato y otros similares no son el eje argumental de su tratado de arquitectura, sino "sketchs" históricos (Granger 1970) sacados a colación al disertar sobre aśpectos técnicos.

Otras cuestiones problemáticas serían la indefinición cronológica del suceso y la circunstancia de que sean los cartagineses y después el tirio Prefasmenos los que utilicen el ariete contra Gadir. En cuanto a la datación, contamos con dos fechas ante quem: la propia invención del ariete, como muy tardía a comienzos del siglo VI a.C. ${ }^{14}$, y el asedio de Filipo de Macedonia contra Bizancio a mediados del siglo IV a.C., especificado en el propio texto.

La interpretación histórica del suceso es ardua pues desconocemos las fuentes utilizadas por Vitruvio y Ateneo. Lo que nos parece incuestionable es que la creación del ariete debe atribuirse a la poliorcética oriental, probablemente con anterioridad al siglo VI a.C., por lo que las elaboraciones de estos autores serían, seguramente, legendarias. Resulta extraño que de una historiografía como la grecolatina, con tan pocas referencias al Extremo Occidente, se hayan conservado nada menos que cuatro relatos de asaltos sufridos por Gadir: además de los de Vitruvio y Ateneo, los de Justino y Macrobio. Salvo los primeros, ninguno coincide en el atacante: Cartago, Hispaniae populis, y Theron rex Hispaniae respectivamente. ¿Es posible que el carácter de finis terrae de Gadir propiciara su reiterada aparición en leyendas y relatos de historicidad dudosa?

\section{VII}

Las transformaciones y contradicciones que tienen lugar en el mundo tardoantiguo se concretan, desde el punto de vista historiográfico, en la existencia paralela y en la fricción entre dos concepciones de la historia y dos modelos de interpretación contrapuestos, uno que lucha por imponerse, el cristiano, y otro por sobrevivir, el grecolatino (Fontana 1982; Orcastegui y Sarasa 1991). A lo largo de los siglos III y, sobre todo, IV se asiste a la paulatina sustitución del modelo grecorromano, no sin ciertas resistencias, evidenciadas en la "reedición" de obras clásicas en forma de epítomes, en el rescate de tradiciones paganas, o en el empleo de un lenguaje arcaizante que contrarreste la creciente vulgarización del latín.

12. Esta noticia está confirmada por Eratóstenes (en Estrabón XVII, 1, 19): “[dice Eratosthénes] que si algún extranjero intentaba navegar hacia Sardó, o por las Columnas, era echado al mar por los karchedónoi. Esta es la razón de que muchas de las cosas que se han dicho sobre el Occidente no sean dignas de crédito" (García y Bellido 1945: 252).

13. El mismo suceso es relatado por Ateneo, autor contemporáneo de Vitruvio (García y Bellido 1945: 85-86). Una referencia tardía al pasaje de Ateneo se encuentra en la bizantina Anna Komnena [Alexias II, 187, 9-12 (Grosse 1959: 393)].

14. La utilización del ariete en el asedio de Tiro por Nabuconodosor es profetizada por Ezequiel $(26,7-9)$ en vísperas del asalto a Jerusalem en el 587 a.C., lo que quiere decir que tanto etariete como la tortuga arietaria ya estaban inventados a comienzos del siglo VI a.C. 
Se continúan antiguos géneros literarios, como el periplográfico y el periegético, que tienen un espíritu más arqueológico, compilatorio y erudito, que verdaderamente científico, y el pasado se transforma a menudo en fábula. Dentro de estos géneros figura la obra de Marciano de Heraclea, que es en realidad una compilación de noticias de geógrafos antiguos como Ps. Escilax, Protágoras, Artemidoro de Efeso, Estrabón y Ptolomeo. La parte dedicada a Iberia incluye una descripción del Estrecho y de Gadir. Parece que extrajo muchos datos de Ptolomeo, a quien podemos atribuir con seguridad el etnónimo bástulo-poeno con el que designa a los habitantes de la costa (Alemany 1910: 391).

En este contexto hemos contemplado los tres últimos autores de tradición clásica que aportan datos sobre la Iberia púnica: Justino, Avieno y Macrobio.

1. Justino redacta un epítome de la historia universal de Pompeyo Trogo, que se componía de 44 libros, el último de los cuales estaba dedicado a Hispania (res Hispaniae et Punicae), compuesto por una descripción geográfica de la Península, la relación de los "reinos de Hispania" o monarquías indígenas, y las conquistas cartaginesa y romana (Hoz 1988: 39). Al parecer, Justino los condensó fielmente, sin añadir datos de su cosecha, recurriendo habitualmente a la omisión de disgresiones, referencias cronológicas y toponímicas, etc., por lo que la narración se torna vaga e indeterminada (García Moreno 1979; Forni y Betinelli 1982; López Castro 1992).

Los sucesos que Justino (XLIV, 5, 1-4) selecciona son tres: la historia de la fundación de Gadir por los tirios tras un oráculo (también en Estrabón III, 5, 5), los conflictos entre gadiritas y pueblos vecinos y el socorro cartaginés, y el desembarco de Amilcar. No hay por qué dudar de la historicidad de ninguno de los pasajes, cuya ordenación depende de la técnica excerptoria del epitomador, pero es imposible sacar conclusiones precisas de orden cronológico. La fecha de la ayuda cartaginesa tan sólo se puede datar con anterioridad al 237 a.C.

2. Rufo Festo Avieno es un poeta pagano cuya personalidad y obra se inserta en el renacimiento constantino-teodosiano o renovatio imperii, una tendencia neoclásica que busca la recuperación de antiguas tradiciones (González Ponce 1995). El género literario de la Ora Maritima no es, como tradicionalmente se ha entendido, el periplográfico, aunque adopte en apariencia la forma del género, muy adecuado para los fines anticuaristas del autor. Su interés no es, pues, ni geográfico ni histórico, sino poético (Hoz 1988: 43). En este sentido, frente a la communis opinio que ve en la Ora Maritima un obra basada en un periplo masaliota de época arcaica, recientemente González Ponce (1995) ha expuesto razones convincentes para desestimar esta hipótesis: la mezcolanza de noticias de distinta naturaleza y cronología, las incongruencias internas del poema, el incumplimiento de los rasgos básicos de un periplo o la inexistencia de este género literario como tal hasta el siglo IV a.C. Por contra adopta un técnica descriptiva escenográfica, más acorde con las intenciones poéticas del autor.

Estas conclusiones no proponen negar la antigüedad de muchas de las fuentes utilizadas por Avieno, hecho que creemos indiscutible, pero sí alejan la posibilidad de que el poema describa la realidad geoetnográfica de Iberia en el siglo VI a.C. Los principales datos que aportaría son:

— identificación de Cádiz con Tartessos (vv. 80-87) ${ }^{15}$.

- los tartesios, los pobladores del área del Estrecho y los colonos de Cartago comercian con los límites de los Oestrymnicos (vv. 107-121).

— los cartagineses ocuparon la isla de Eritia y ciudades "más acá de las Columnas de Hércules" (vv. 303-317 y 375-383).

- las inmediaciones del río Criso están habitadas por libifénices, masienos, cibilcenos y tartesios, y Málaca se identifica con Ménaca (vv. 416-431).

15. Reproduce una vieja polémica ya presente en Plinio (NHIV, 120), paralela a otra que la identifica con Carteia: Plinio ( $N H$ III, 7) y Mela (II, 96). 
- cercana al puerto Namnatio se halla una ciudad massiena; los fenicios habitaron en un principio estos lugares, próximos al río Teodoro (vv. 449-460).

3. Macrobio presenta un talante literario diferente al de los autores anteriores, aunque como Avieno era pagano y representante de la corriente de renovación clasicista. La información que nos ha aportado se reduce a un breve texto (Sat. I, 20,12) que, de manera inversamente proporcional a su importancia como fuente, se ha convertido en uno de los documentos más valorados por la historiografía española de todos los tiempos. En él se narra el asalto de Theron, Rex Hispaniae Citerioris, al templo de Cádiz, y su derrota y huida por sucesos extraordinarios.

Este episodio está inserto en el primero de los siete libros que conforman los Saturnalia, un relato resuelto al estilo del banquete platónico donde se mantiene un diálogo en el que se habla del sincretismo solar y de los dioses que se relacionan con su culto, Hércules entre ellos. En este contexto se incorpora el asalto al templo de Hércules, un argumento válido para la demostración del poder del dios (Alvar 1986: 161).

La historiografía española lo ha asociado habitualmente al pasaje de Justino; incluso se ha llegado a afirmar que Theron "es un régulo contestano de mediados del siglo IV que, probablemente con ayuda de las comunidades griegas del Levante peninsular, pretendió hacerse con la ciudad de Cádiz, pero fracasó en su intento" (Alvar 1986: 175); o que "la aventura de Terón,.., ha de ponerse en relación con la tendencia hacia una nueva unificación, hacia una nueva Tartessos" (Castillo 1993: 61).

Nuestra postura es muy escéptica en lo que se refiere a la posibilidad de extraer alguna información históricamente válida. Primeramente porque el autor, que escribe hacia el 400, no pretendió redactar una obra histórica, sino didáctica y pedagógica, con una intención anticuarista visible en la estructura narrativa y en los términos empleados (Garrido 1990). Por otro lado, ni el contexto -la descripción de los ritos solares-, ni la narración, sin referencias cronológicas ni a las fuentes originales, permiten ir más allá de la anotación del dato.

\section{DISCUSIÓN: RELACIÓN ENTRE GEOGRAFÍA Y ETNONIMIA EN EL SUR DE IBERIA SEGÚN LA LITERATURA GRECOLATINA}

Examinada la documentación, hemos podido comprobar que los pueblos que habitaron la franja costera del sur de Iberia fueron denominados de diferente manera: mastienos, etíopes occidentales, púnicos, cartagineses, libiofenicios, bastetanos, bástulos, blastofenicios, bástulo-poenos. Esta disparidad etnonímica conduce a la confusión e invita a pensar que, o se sucedieron varios pueblos en la habitación de la costa durante la segunda mitad del $\mathrm{I}^{\mathrm{er}}$ milenio a.C., que es el período historiográfico abarcado, o bien se emplearon distintos términos para denominar a un mismo pueblo. Por razones obvias, esta última hipótesis es la que nos parece más pausible y explicable a partir de una ordenación de la documentación según los etnónimos:

1. Los autores más antiguos, Hecateo, Herodoro y Teopompo, hablan de mastienos o massienos, junto a tartesios y elbestios/ elbysinos. Las poleis mastienas (Suel, Menobara, Sixo, Molibdano) se identifican sin duda con las antiguas ciudades fenicias (Gozalbes 1983:41), que adquirirán este etnónimo por el liderazgo de Mastia. En este grupo habría que incluir los testimonios de Polibio referidos a Mastia y a los tartesios, remontables al siglo IV a.C.

La última mención a los mastienos la hace Avieno, en cuya obra se han combinado una serie de elementos comunes a Hecateo, Herodoro y Teopompo, que remontan como pronto al siglo IV a.C.

2. Los etíopes occidentales aparecen en Eforo, en el siglo IV a.C., y en Escimno, Dionisio Periégeta (siglo II d.C.) y Avieno, cuyos "periplos" parecen muy inspirados en la obra de Eforo o en su tradición. Para algunos autores la existencia de estos etíopes, norteafricanos al fin y al cabo, significaría sin duda la presencia de cartagineses en las costas de Iberia (Frutos 1991: 65). En nuestra opinión el pasaje no tendría 
este valor, y el testimonio de Estrabón (I, 2, 26) es el que puede darnos la clave: la idea de etíopes divididos en dos grupos, unos en Libia y otros en Iberia, parece que se remonta a los relatos homéricos, cuya tradición seguiría Eforo, mal conocedor de la realidad geoetnográfica de Iberia; Escimno sería el continuador de Eforo, como Dionisio Periégeta lo fue de Escimno y Avieno de Dionisio. Los tres últimos autores cultivan un género literario visiblemente fosilizado y se limitan a transmitir una información mítica.

3. Otro bloque de testimonios pertenece cronológicamente al momento de entrada de Iberia en la órbita romana, hecho que significaría la apertura definitiva del Extremo Occidente al mundo grecolatino y la multiplicación de la información. Hemos podido comprobar cómo los etnónimos se han transformado. Ahora los pueblos que habitan las costas andaluzas son, para Estrabón, bastetanos o bástulos, y para Plinio y Mela, bástulos. También aparecerán fórmulas mixtas que, a nuestro juicio, no hacen sino redundar en el carácter semita de los bastetanos/bástulos: blastofenicios en Apiano, bástulos llamados púnicos en Ptolomeo y, en Marciano, bástulo-poenos.

En opinión de García Moreno (1993: 210) esta transformación se debe a que el etnónimo bastetano, desde el punto de vista lingüístico, es la versión latina de mastieno, al igual que turdetanos y túrdulos vienen a sustituir a tartesios, de manera que mastienos y tartesios eran los etnónimos empleados por autores griegos, probablemente a través de intermediarios púnicos, con anterioridad a la segunda Guerra Púnica, mientras que bastetanos/bástulos y turdetanos/túrdulos serían los mismos pueblos pero llamados así por los autores clásicos una vez concluida la conquista. Se trataría de un problema de doble transcripción de un mismo etnónimo.

4. En realidad la referencia más explícita de la pertenencia de las costas del sur Iberia a los púnicos es la de Agripa. A éstas habría que añadir las continuas alusiones de Estrabón a la presencia semita en estos territorios tras la conquista romana, y los versos de Avieno en los que también nos habla de poblaciones fenicias y cartaginesas.

5. Las relaciones entre Cartago y las comunidades púnicas de Iberia constituye otro conjunto heterogéneo de noticias. El pasaje de Justino del socorro cartaginés a Gadir y la posterior conquista de parte del territorio circundante es un dato de interés sobre la estrecha relación entre ambas metrópolis. Nuevos testimonios de intereses cartagineses en la Península pueden deducirse de algún pasaje de Heródoto (IV, 196), del tratado del 348 a.C. referido por Polibio, de la noticia del pseudo aristotélico De mirabiles auscultationes, del testimonio de Eratóstenes o de algunos pasajes de Diodoro Sículo. En todos está presente no tanto la idea de una colonización o conquista cartaginesa de la Iberia púnica, como la de comercio, navegaciones, descubrimientos, intereses económicos y cierta autoridad política sobre estos territorios.

6. Por último, los libiofenicios aparecen en cuatro ocasiones asentados en Iberia, con el nexo común de que los cuatro testimonios son posteriores a la segunda Guerra Púnica: Escimno, Polibio, Tito Livio y Avieno. En Polibio (III, 33, 14-16) y en Tito Livio los libiofenicios se relacionan claramente con la política anibálica de deportaciones y rehenes en Iberia. Aparecen enrolados en un gran ejército asentado en el sur de Iberia con el fin de no desguarnecer la defensa de sus conquistas, compuesto por un combinado "internacional" con predominio norteafricano, en el que figuran además de los 450 jinetes libiofenicios, más de 11.000 infantes norteafricanos, y baleares, ligures, númidas, moros e ilergetes.

En lo que se refiere a las obras de Escimno y de Avieno, ambas tienen en común la mezcla arbitraria de noticias antiguas y recientes, sin seguir un orden geográfico ni étnico correcto en la descripción de las costas. En ninguno de las dos se pretendió exponer una geografía real, sino evocar poética o pedagógicamente recurriendo al anticuarismo. No hay razones, pues, para pensar en una colonización agrícola cartaginesa en el área de Gadir a partir del siglo VI a.C. (López Castro 1992), ni en conceptos distintos del término según las épocas (Domínguez Monedero 1986).

Los libiofenicios serían un grupo humano mixtum punicum africanum utilizado por el estado cartaginés para colonizar en otras ocasiones (es el caso del periplo de Hannon), pero que en Iberia fueron requeridos 
para cumplir tareas militares. No debieron constituir un contingente muy numeroso con respecto a los demás mercenarios, y con probabilidad se integraron rápidamente con la población púnica autóctona, o bien retornaron a su lugar de origen una vez finalizadas las hostilidades.

\section{CONCLUSIÓN: TEMAS Y CICLOS GRECOLATINOS SOBRE IBERIA}

Analizada globalmente, la historiografía grecolatina que se ocupa de los temas relacionados con el Extremo Occidente debió ser muy limitada y estar mediatizada por su condición de frontera del mundo conocido durante el período anterior a la conquista romana (Pontrera 1990: $55 \mathrm{ss}$.). Si a este fenómeno le sumamos el desinterés general de la historiografía griega por otros pueblos, las especiales condiciones de la producción literaria, o la inclusión del sur de Iberia en el área cultural fenicio-púnica, no es de extrañar que las noticias sean tan monótonas, difusas e inexactas.

El grueso de la información podría ser clasificado en varios grupos temáticos. Entre ellos destaca todo lo relacionado con Gadir, con su origen, situación, descripción, e industrias salazoneras ${ }^{16}$.. Pero no todos estos aspectos son tratados de igual manera. Hay gran interés científico a través de la investigación empírica, sobre todo después de la conquista romana, por todo lo referente a los fenómenos naturales (mareas, ocultamiento de sol) y a la geografía de las islas y del estrecho de Gibraltar.

Paralelo a este interés hay un fenómeno de mitificación. Gadir es la última ciudad del mundo conocido y las Columnas de Heracles el límite de la ecúmene con la inmensidad del Océano; en ellas y en sus inmediaciones poetas, geógrafos e historiadores situarán los mitos grecolatinos. Uno de las tradiciones más arraigadas en la mitología clásica es el solar; el ocaso del sol por Occidente fue el principal fundamento para la formación de fábulas (Jiménez 1971). El pasaje de Macrobio puede ser incluido en este grupo.

Otro grupo de testimonios puede clasificarse como descripciones geoetnográficas de las costas de Iberia, contenidas básicamente en dos géneros literarios: la periégesis y el periplo. Este conjunto presenta la problemática de su evolución interna, siendo imprescindible conocer el proceso evolutivo de ambos géneros para distinguir entre la creación de un modelo (por ejemplo, la obra de Hecateo de Mileto), su continuación (Herodoro, Teopompo), su posible adaptación a las nuevas realidades etnonímicas, o la estandarización y adulteración del modelo, que presentaría numerosas contaminaciones (Escimno, Dionisio Periégeta, Marciano de Heraclea, Avieno).

Por último, la Geographiká de Estrabón sería el ejemplo más ilustrativo de la situación de Hispania en los siglos II y I a.C., en la que pueden observarse la perduración púnica en las costas y la profunda huella dejada por los semitas en Turdetania.

\section{BIBLIOGRAFÍA}

ALEMANY, J. (1909): "La geografía de la Península Ibérica en los textos de los escritores griegos, desde que éstos tuvieron conocimiento de aquélla, hasta el siglo II a.C." RABM XXI, 463-477. Madrid.

(1910): "La Geografía de la Península Ibérica en los textos de los escritores griegos" $R A B M X X I I$, $1-34$ y $360-371$.

ALVAR, J. (1986): "Theron, rex Hispaniae Citerioris (Macr. Sat. I, 20, 12)" Gerión 4, 161-175. Madrid.

16. El tema de la calidad de los salazones de Gadir aporta testimonios reveladores y fiables sobre la popularidad de las producciones desde el siglo V a.C. No obstante, como otros temas, durante la fase tardía de la historiografía grecolatina sufrió un proceso de "fosilización", repitiéndose la información reiterativamente, lo que explicaría que en tiempos de la bizantina Alexia Konmena todavía se siguiesen alabando las salsas de pescado de Gades. 
BALASCH, M. (1981): Polibio. Historias. Libros I-IV. Madrid.

CASARIEGO, J.E. (1949): Los grandes periplos de la Antigüedad. Madrid.

CÀSSOLA, F. (1983): "Tendenze filopuniche e antipuniche in Roma" I CISFP I, 35-59. Roma.

CASTILLO, A. DEL (1993): "El rey Terón y la situación de la península en época postartésica” $R S F$ XXI suppl., 53-62. Roma.

DÍAZ TEJERA, A. (1981): "Introducción" Polibio. Historias. Libros I-IV. Ed. Gredos. Madrid.

DOMÍNGUEZMONEDERO, A. (1986): "Los libiofenicios y la interpretación del significado de su presencia en el sur peninsular" Actas del I Congreso Hispano-Africano de Culturas Mediterráneas, 129-138. Granada. (1988): "Píndaro y las Columnas de Heracles" Actas del I CIEG I, 711-724. Madrid.

DREWS, R. (1962): "Diodorus and his sources" AJPh 83, 383-392. Baltimore.

DUBUISSON, M. (1983): "L'image du carthaginois dans la littérature latine” Studia Phoenicia I-II, 156-166. EDMONDS, (1957): The Fragments of Attic Comedy. Leiden.

FABRE, P. (1965): "La date de la rédaction du périple de Scylax" Les Etudes Classiques XXXIII, 4, 353-366. FERNÁNDEZ NIETO, J. (1992): “Griegos y colonización griega en la Península Ibérica" Griegos en Occidente, 129-145. Sevilla.

FERNÁNDEZUBIÑA, J. (1986): "Herodoto y la etnografía del Mediterráneo Occidental" I Coloquio HispanoAfricano de las Culturas Mediterráneas, 139-147. Granada.

FERRER ALBELDA, E. (1995): Los púnicos en Iberia: Análisis historiográfico y arqueológico de la presencia púnica en el sur de la Península Ibérica. Tesis Doctoral (inédita). Sevilla.

- (1996): La España Cartaginesa. Claves historiográficas para la Historia de España. Sevilla.

FERRER, E. y BANDERA, Mª . L. (1997): "La localización de Mastia: un aspecto problemático de los conocimientos geográficos griegos sobre Iberia". X $\alpha \hat{\imath} \rho \varepsilon$. Homenaje al Prof. F. Gascó, 64-72. Sevilla. FONTANA, J. (1982): Historia. Análisis del pasado y proyecto social. Barcelona.

FORNI, G. y BETINELLI, Ma.G.A. (1982): "Pompeo Trogo come fonte di storia" ANRWII.30.2, 1298-1362. FRUTOS, G. DE (1991): Cartago y la política colonial. Los casos norteafricano e hispano. Écija.

— y MUÑOZ, A. (1994): "Hornos púnicos de Torre Alta (San Fernando, Cádiz)" Arqueología en el entorno del Bajo Guadiana, 375-392. Huelva.

GARCÍA MORENO, L.A. (1979): "Justino 44, 4 y la historia interna de Tartessos" AEspA 52, 111-130. Madrid.

- (1989a): "La Hispania anterior a nuestra Era: verdad, ficción y prejuicio en la historiografía antigua y moderna" Actas del VII Congreso Español de Estudios Clásicos III, 17-43. Madrid.

- (1989b): "Turdetanos, túrdulos y tartessios. Una hipótesis" Estudios sobre la Antigüedad en homenaje al prof. S. Montero Díaz. Anejos de Gerión II, 289-294. Madrid.

- (1993): "Mastienos y bastetanos: un problema de la etnología hispana prerromana" I Coloquio de Historia Antigua de Andalucía I, 201-211. Córdoba.

GARCÍA Y BELLIDO, A. (1945): España y los españoles hace dos mil años según la "Geografía" de Strabon. Madrid.

— (1947): La España del siglo primero de nuestra Era (según P. Mela y C. Plinio). Madrid. (1951): "Iocosae Gades" BRAH CXXIX, 73-122. Madrid.

(1954): "La colonización cartaginesa desde sus comienzos (fundación de Ibiza, 654) hasta la conquista cartaginesa (237)" Historia de España Menéndez Pidal. Protohistoria II, 337-492. Madrid.

GARRIDO LÓPEZ, C. (1990): La lengua de Macrobio. Madrid.

GIL, J. (1986): "Recensión a M. Koch, Tartschisch und Hispaninen. Berlín, 1984" Gerión 4, 378-380. Madrid. GONZÁLEZ PONCE, F.J. (1995): Avieno y el periplo. Écija.

GONZÁLEZ WAGNER, C. (1983): Fenicios y Cartagineses en la Península Ibérica. Madrid.

(1986): "Tartessos y las tradiciones literarias" $R S F$ XIV, 2, 201-228. Roma.

GOZALBES CRAVIOTO, E. (1983): “Málaga, ciudad púnica: las fuentes literarias” Jábega 41, 3-10. Málaga. 
GRANGER, F. (1931): Vitruvius I. De architectura II. Londres (ed. 1970).

HOZ, J. DE (1971): "Notas sobre las fuentes para la Historia Antigua de España" Habis 2, 137-141. Sevilla. (1989): "Las fuentes escritas sobre Tartessos" Tartessos, 25-43. Sabadell.

INIESTA SANMARTÍN, A. (1989): "Notas para la reconstrucción del área mastieno bastetana en el sureste peninsular" XIX CNA, 1129-1140. Zaragoza.

JACOBY, F. (1968): Die Fragmente der Griechischen Historiker. Leiden.

JIMÉNEZ CISNEROS, M.J. (1971): Historia de Cádiz en la Antigüedad. Cádiz.

KRINGS, V. (1990): "Les Libri Punici de Salluste" L'Africa Romana. Atti del VII Convegno di Studio I, 109-117. Sassari.

LANCEL, S. (1994): Cartago. Ed. Crítica. Barcelona.

LÓPEZ CASTRO, J.L. (1992): "Pompeyo Trogo (Justino XLIV, 5, 1-4) y el imperialismo cartaginés en la península ibérica" In memoriam J. Cabrera Moreno, 219-235. Granada.

— (1992b): "Los libiofenicios: una colonización agrícola cartaginesa en el sur de la península ibérica" RSF XX, 1, 47-65.

LOPEZ PARDO, F. (1991): "El periplo de Hannon y la expansión cartaginesa en el África Occidental" $\checkmark$ Jornadas de Arqueología Fenicio-Púnica, 59-72. Ibiza.

MAZZARINO, S. (1966): Il pensiero storico classico. Bari.

MOMIGLIANO, A. (1984): La historiografía griega. Barcelona.

MOSCATI, S. (1983): Cartagineses. Madrid.

ORCASTEGUI, C. y SARASA, E. (1991): La Historia en la Edad Media. Madrid.

PARETTI, A. (1983): "I peripli arcaici e Scilace de Carianda" Geografia e geografi nel mondo antico. Guida storica e critica, 70-112. Roma-Bari.

PEDECH, P. (1952): "Sur les sources de Polybe: Polybe et Philinos" REA 54, 246-266. Amsterdam.

PLÁCIDO, D. (1993): "Los viajes griegos al Extremo Occidente: del mito a la Historia" I Congreso de Historia Antigua de Andalucía I, 173-180. Córdoba.

PRONTERA, F. (1990): "L'estremo occidente nella concezione geografica dei greci" La Magna Grecia e il lontano Occidente. Atti del XXIX Convegno di studi sulla Magna Grecia, 55 ss.

RODRÍGUEZ ADRADOS, F. (1986): Herodoto. Historias. Libros I-II. Madrid.

RODRÍGUEZ MOHEDANO, F.P. Y F.R. (1766): Historia Literaria de España I. Madrid.

SACKS, K. (1990): Diodorus Siculus and the first century. Princeton.

SCHEPENS, G. (1985): “The Phoenicians in Ephorus' Universal History” Studia Phoenicia V, 315-330.

SCHULTEN, A. (1945): Tartessos. Madrid (ed. 1972).

- y BOSCH GIMPERA, P. (1922): Fontes Hispaniae Antiquae I. Barcelona.

SILGO GAUCHE, L. (1992): "Los límites étnicos de la Turdetania" Estudios de Arqueología ibérica y romana. Homenaje a Enrique Pla Ballester, 365-372. Valencia.

VALLEJO, J. (1954): "Polibio y la geografía de España" Emerita 22, 278-282.

VILLALBA I VARNEDA, P. (1985): "El periplo en la Antiguiedad" BMAN III, 43-49. Madrid.

WALBANK, F.W. (1957): A historical commentary on Polybius. Oxford. 